\title{
Where in the world? A geographic analysis of a decade of research in tourism, hospitality and leisure journals
}

\section{ABSTRACT}

This study examined research focus countries and regions in 4,654 articles published in 32 tourism, hospitality and leisure academic journals from 2002 to 2011 inclusive. Applying a variety of analysis methods, the research showed the spatial distribution, co-occurrence relationships among countries, and the most popular topics of research focus and types of tourism by countries. There was a broad geographic focus of the research in tourism, hospitality and leisure journals in the decade from 2002 to 2011 spanning 126 countries. It was found that a significant number (70) of countries were not covered in this 10-year snapshot of the academic journal research and require more attention from scholars in the future. Some major countries were under-represented including France, Germany, and Russia. However, the predominance of the research focus on the Asia-Pacific region and particularly on China was a major finding in this analysis, as was the sparse coverage of South and Central America.

Keywords:

Academic journals; bibliometrics; co-occurrence relationships; NetDraw; spatial distribution analysis; tourism system

\section{Introduction}

Since 1946, English-language journals have played a significant role in expanding tourism academic scholarship (Xiao \& Smith, 2006). As the major platform for academic research communications, journals not only include individual articles by a variety of scholars, but also reflect the range and relative popularity of topics of tourism research during specific time periods and for certain geographic areas. Van Doren, Koh, and McCahill (1994, p. 308) suggested that "research journals are considered to be the major showcase of research in the field." The characteristics and trends of tourism research can be determined by analyzing tourism academic journals (Dai, Tang, \& Du, 2011).

There have been many previous studies examining selected journals to describe particular characteristics of tourism research. Many of these studies have focused on the productivity of individual tourism scholars and their institutional affiliations (Jogaratnam, McCleary, Mena, \& Yoo, 2005a; Park, Phillips, Canter, \& Abbott, 2011; Ryan, 2005). While there are now 70-plus tourism journals being published in English, most previous studies have been based on three major journals, Tourism Management, Annals of Tourism Research, and Journal of Travel Research. These journals are 
among the highest ranked in SSCI and they were all launched from 1968 to 1974, so they carry a long and rich history of research publication in tourism.

Most of the past research on tourism journals is based on the analysis of keywords. Author-selected keywords reflect the major topics in articles and they draw concise and precise pictures of the research (Banville \& Landry, 1989). Moreover, keywords summarize the most important information in articles and highlight research situations, disciplines, trends, and increasingly popular topics (Yin, Zhang, \& Li, 2009). The quantitative analysis of keywords displays the disciplinary characteristics of tourism research and previous scholars have attached great importance to the overall features of tourism research.

Region, country, city, attraction, site and other place names included in article keywords, titles, and bodies can be analyzed to show where tourism research is being conducted and which parts of the world are receiving the greatest and least attention from tourism scholars. Despite the importance of geographic information in characterizing tourism research, it has largely been neglected in previous studies. These analyses can help direct future researchers on where to geographically focus their inquiries to make unique contributions to the tourism, hospitality and leisure literature and practice. Further insights can be gained by measuring the research topics and types of tourism that have been addressed by country and region. There have been several studies examining the collaboration among tourism scholars (for example, Leung, Leung, Bai, \& Law, 2011; Ye, Li, \& Law, 2013); however little attention has been given to combinations of countries and regions in tourism research. In addition, research focus countries and regions analysis can also demonstrate the most popular geographic comparisons by measuring co-occurrence relationships. To fill the identified gap in previous studies, four specific research objectives were identified:

1. What are the spatial distributions of published research studies in academic journals according to focus countries and regions?

2. What are the co-occurrence relationships among research focus countries?

3. What are the most popular research topics for research focus countries?

4. Which types of tourism are covered for research focus countries?

\section{Literature review}

\subsection{Prior studies on tourism academic journal research}

Prior studies on tourism academic journal research have generally concentrated on two aspects. The first concentration has been the overall evaluation of journals to produce rankings or ratings of individual academics, journals, and university 
programs, and perceptions of journal quality (Cheng, Li, Petrick, \& O'Leary, 2011; Frechtling, 2004; Hall, 2011; Jamal, Smith, \& Watson, 2008; McKercher, Law, \& Lam, 2006; McKercher, 2005; Murphy \& Law, 2008; Palmer, Sesé, \& Montaño, 2005; Pechlaner, Zehrer, Matzler, \& Abfalter, 2004; Ryan, 2005; Schmidgall \& Woods, 1993; Sheldon, 1990; Tribe \& Xiao, 2011). The second concentration has been on statistically analyzing journal contents to find the most popular topics in tourism research, as well as ranking authors and their affiliations (Hu \& Racherla, 2008; Jogaratnam, Chon, McCleary, Mena, \& Yoo, 2005b; Lee \& Law, 2011; Park et al., 2011; Racherla \& Hu, 2010; Samenfink \& Rutherford, 2002; Severt, Tesone, Bottorff, \& Carpenter, 2009; Sheldon, 1991).

Tourism journal studies are published covering a wide assortment of topics. These topics have included citations (Kim, Savage, Howey, \& Van Hoof, 2009; Xiao \& Smith, 2008); tourism knowledge domains (Ballantyne, Packer, \& Axelsen, 2009; Wu, Xiao, Dong, Wang, \& Xue, 2012; Xiao \& Smith, 2005); keyword frequency and research "hot-spots" (Dai et al., 2011; Wu et al., 2012); analysis methods (Crawford-Welch \& McCleary, 1992; Dann, Nash, \& Pearce, 1988; Faulkner \& Ryan, 1999; Palmer et al., 2005; Rivera \& Upchurch, 2008; Wu et al., 2012); contributions of authors and affiliations (Jogaratnam et al., 2005a; Jogaratnam et al., 2005b; Park et al., 2011; Ryan, 2005; Sheldon, 1991; Xiao, Li \& Lin, 2011); tourism research collaborations (Racherla \& Hu, 2010; Ye, Li, \& Law, 2013); and distribution of authors' affiliations (Jogaratnam et al., 2005b, Park et al., 2011; Sheldon, 1991). In addition, scholars have investigated doctoral dissertation topics and research fields (Botterill, Haven, \& Gale, 2002; Crichton, 1978; Jafari \& Aaser, 1988; Meyer-Arendt \& Justice, 2002).

Most of the scholars conducted their research using the databases of Tourism Management, Annals of Tourism Research, and Journal of Travel Research (Reid \& Andereck, 1989; Jogaratnam et al., 2005b; Sheldon, 1991; Wu et al., 2012). Their databases were generally composed of 1,000-3,000 articles (Jogaratnam et al., 2005b; Palmer et al., 2005; Sheldon, 1991; Wu et al., 2012). However, some other scholars have carried out analyses using more than three journals. Crawford-Welch \& McCleary (1992) analyzed five leading hospitality-related journals; Pechlaner et al. (2004) considered 22 tourism and hospitality journals; Palmer et al. (2005) reviewed 12 tourism journals published from 1998-2002; Ryan (2005) assessed 16 tourism journals; Jogaratnam et al. (2005b) examined 11 leading hospitality and tourism journals; and Svensson, Svaeri \& Einarsen (2009), Ye et al. (2013), and Park et al. (2011) each looked at six tourism and hospitality journals. 


\subsection{Frameworks and typologies of tourism research}

A variety of different approaches have been adopted to classify previous tourism research studies into categories. Pearce (2012, p. 10-16) identified seven alternative frameworks for tourism research including theoretical; conceptual; analytical; integrative; process; systems, networks and composite; and multi-purpose matrices. He suggests that, "Frameworks are the foundation of good scholarship. They structure, organize and communicate research, underpin individual studies and shape the field of study as a whole" (Pearce, 2012, back cover). From Pearce's work, it can be concluded that there are alternative ways to categorize the research articles that are published in tourism, hospitality and leisure journals.

Several previous studies have attempted to classify published academic articles in tourism. For example, Xiao and Smith (2006) analyzed the comprehensive subject index of Annals of Tourism Research over a 30-year period (1973-2003). They found two meta-categories of tourism knowledge domains: methodology and theoretical constructs, and development and impacts. Wu et al. (2012), using keyword analysis in Annals of Tourism Research (from 1978-2009), Journal of Travel Research (from 2003-2009), and Tourism Management (from 1982-2009), set out to identify tourism knowledge domains. They identified 200 top keywords appearing more than seven times each and then classified these into geographical areas (28), subject areas (42), theories and methods (18), and knowledge domains (112). Ten "gene words" were found that were tourism, tourist, development, market/marketing, destination, cultural/culture, impact, economics/economic/economy, management, and social/society.

There have also been many previous attempts to create typologies in an assortment of component fields and topics within tourism. For example, these have included agritourism (Philip, Hunter, \& Blackstock, 2010); backpacking experiences (Uriely, Yonay, \& Simchai, 2002); cultural tourism (McKercher \& du Cros, 2003); dark tourism (Stone, 2006); special interest tourism (Trauer, 2006); tourist attractions (Lew, 1987); as well as many recommended typologies of tourists. Groupings of tourism research topics are also found in research reviews, frameworks, and agendas including, for example, for urban tourism (Ashworth \& Page, 2011; Edwards, Griffin, \& Hayllar, 2008; and Pearce, 2001).

It is noteworthy from the review of these studies, that there has been an absence of attempts to characterize tourism research across different countries or world regions. The main focus has been on the journals, specific tourism topics, and the research productivity of individual scholars and academic institutions. 


\subsection{Systems framework approaches and the tourism system}

As suggested by Pearce (2012), a systems approach can be employed as a framework for describing tourism research. In this respect, the tourism system as an academic concept appears to be accepted by scholars, although there is no consensus on its definition, composition, structure, function, and characteristics. Scholars began to discuss the tourism system in the 1970s and several types of tourism system models have been proposed. Gunn (1972) first proposed a tourism system including supply and demand from the view of "structure-function." In 2002, this model was modified and an emphasis was placed on the relationship between supply and demand. In the new tourism system model, there were a demand-side component (population) and four supply-side components (information-promotion, transportation, attractions, and services) (Gunn \& Var, 2002).

Leiper (1979) put forward another tourism system model based on the relationship of tourists and destinations. The tourism system model included tourists, the tourism industry, and tourist generating regions, travel channels and destinations. Unlike Gunn's model, Leiper highlighted spatial elements including tourist generating regions, travel channels and destinations.

Mill and Morrison (1985) introduced another model in the textbook, The Tourism System. Mill and Morrison's (2012) tourism system consists of four parts (destination, marketing, demand, and travel) and four links (the tourism product; the promotion of travel; the travel purchase; and the shape of travel). This model was more comprehensive and complete than previous models since it introduced other concepts including marketing and consumer behavior, and sustainable tourism development, while also acknowledging the open-system nature of tourism and the major impacts of externalities. Benckendorff and Zehrer (2013, p. 137) found this textbook to be the most highly cited from 1996-2010 in Annals of Tourism Research, Journal of Travel Research, and Tourism Management. The Tourism System Model provides in-depth coverage of many research subject areas and therefore can fully support a subject area categorization framework.

\section{Methodology}

\subsection{Journal selection}

At the time of this research there were approximately 75 major English-language tourism, hospitality, and leisure journals. A preliminary journal list was developed based on a review of the literature (Crawford-Welch \& McCleary, 1992; Hall, 2011; Jogaratnam et al., 2005a; Palmer et al., 2005; Park et al., 2011; Svensson et al., 2009; Ye, Li, \& Law, 2013). The list included the tourism journals documented by Morrison 
(2004) as cited by McKercher et al. (2006). The final list of 32 journals was comprised of 16 SSCI journals and 16 non-SSCI journals which were frequently mentioned in the previous research (Table 1). The equal number of SSCI and non-SSCI journals was to give a balanced coverage of both journal types. The first group included all the SSCI-listed journals at the time of conducting the research.

\section{[Insert Table 1 about here]}

\subsection{Research article classification}

To explore the relationships of academic journal article topics and research focus countries, author-selected keywords were coded and double-checked by six researchers. Fifty-three sub-categories were derived from Mill and Morrison's The Tourism System and the Encyclopedia of Tourism (Jafari, 2000; Jafari \& Xiao, 2015). The 53 sub-categories were placed into four categories based on their most salient attributes. The specific rule of only classifying each keyword into one sub-category was set for the all researchers to consistently follow. For example, satisfaction levels and customer loyalty were classified into demand instead of marketing because these were judged to be closer to customers' perceptions rather than marketing or promotion. A generic category was added to the framework to collect keywords that applied to more than one or all of the system parts such as tourism and tourists, as well as real names (Figure 1).

\section{[Insert Figure 1 about here]}

\subsection{Identification of research focus countries}

A research article database was created consisting of 9,514 articles spanning the 10 years from 2002-2011. Geographic references were extracted from the keywords, titles, and body text of articles to create databases of research focus countries and regions. In order to explore the spatial characteristics and co-occurrence relationships of research focus countries, the 9,514 articles were reviewed and an initial database including 2,531 articles with geographic keywords (region, country, city, and place names). Articles with geographic information in titles but without geographic keywords were also included in an augmented database comprising 3,896 articles. Another 1,123 articles (20\%) were selected randomly from the remaining 5,618 articles without geographic references in both keywords and article titles. The body text of these 1,123 articles was reviewed to abstract geographic references. 
Approximately one-third of the sampled articles included geographic references; 294 out of 869 SSCI and 79 out of 254 non-SSCI journal articles. Most of the articles without geographic references were theoretical studies or produced general results; for example a model construction article (Sun, 2007) and research on information asymmetry in customers' booking decisions (Chen \& Schwartz, 2006).

The 373 articles with geographic references out of 1,123 were added to the augmented database comprising 4,269 articles. In total, the analysis covered 5,019 journal articles. The remaining 4,495 articles without geographic keywords and titles in the 32 journals were not reviewed. If the $33 \%$ ratio was to remain true for these remaining articles, there were potentially another 1,483 articles with geographic references that were not included in this analysis.

Regional names included Europe/European Union/Mediterranean, Asia, Pacific, North America, South America, Caribbean and Antarctic. The cities and places listed by authors as keywords and in titles were classified into their respective countries. In total, 126 research focus countries were identified. There were approximately 4,500 country references in the final country database, so the average frequency per country was approximately 36 . Some articles included both place, city and country names, but in these cases the country was counted only once. There were a large number of articles with country references of China and its component territories. Hong Kong and Macau were coded as China; the keywords of England, Scotland, Wales and Northern Ireland were coded as the United Kingdom (UK).

In order to gain insights into differences of research focus countries and regions in 16 SSCI journals and 16 non-SSCI journals, the database was classified into two groups and compared.

\subsection{Data analysis}

Four analytical methods were applied in this research. First, bibliometric analysis was used to count the frequency of keywords. Bibliometric analysis was put forward by Pritchard (1969) as "the quantitative study of physical published units, or of bibliographic units, or of the surrogates for either" (Broadus, 1987, p. 376). It has been widely applied in tourism studies (Hall, 2011). Because the number of keywords in the database was beyond threshold value of some software (e.g., CATPAC), Excel was used to analyze the data. Spatial distribution analysis was applied to visualize the research focus countries and a diagrammatic spatial distribution map was drawn. NetDraw analysis (Borgatti, 2002) explored the co-occurrence relationships of research focus countries. Cross-tabulations were prepared to compare the most popular research topics across the research focus countries with the highest frequencies of keywords. 


\section{Research results and findings}

\subsection{Spatial distribution characteristics of research focus countries and regions}

Research focus countries were analyzed base on the database including 4,296 articles with geographic references. There were 126 research focus countries in total. There being 196 independent entities in the world (U.S. Department of State, 2013), it can be stated that 70 were not the focus on any research in the 32 journals from 2002-2011. Other geographic entities with articles were Antarctica and Palestine.

There were some differences between the SSCI and non-SSCI journals in terms of research focus countries. The 16 SSCI journals had 121 research focus countries with an average frequency of 26 per country, while the 16 non-SSCI journals had 102 focus countries with an average frequency of 13 (Table 2). The SSCI journals covered a wider set of countries and these countries had more in-depth coverage compared with the non-SSCI journals.

For the SSCI journal database, China and the USA were the two research focus countries with the highest frequencies at 509 and 411 respectively; the UK (273) and Australia (245) were third and fourth. Taiwan (138), Spain (131), Canada (104), New Zealand (96), South Korea (95), and Turkey (76) ranked fifth to tenth for the SSCI journals. At the lower end, there were 80 countries with frequencies between 1 and 10 and 21 countries had only one geographic reference in the SSCI journal database. Five countries covered in the non-SSCI database were not included in the SSCI database.

In terms of non-SSCI database, China (147), USA (138), Australia (118), and UK (111) had the highest frequencies. The top 10 frequencies for non-SSCI journals were similar, but Japan and Thailand were included and Canada and New Zealand were not.

\section{[Insert Table 2 about here]}

Table 3 indicates that tourism research on Asia, Europe, Oceania, and North America was the most frequent, while there were much fewer articles with a focus on South and Central America, the Middle East, the Caribbean, and the Antarctic. Asia-Pacific was the top research focus region for both SSCI and non-SSCI journals with percentage of $44.8 \%$ and $39.5 \%$ respectively. The percentage for Europe was higher in non-SSCI journals (34.5\%) compared with SSCI journals (27\%). North America was the focus for $16.8 \%$ of the articles in the SSCI database, while the percentage for non-SSCI was $11.7 \%$.

\section{[Insert Table 3 about here]}

The SSCI journals and non-SSCI journals database were combined to explore general characteristics of research focus regions and countries in 32 journals. The 
diagrammatic spatial distribution map of the frequencies for research focus countries is shown in Figure 2. This map visually demonstrates that tourism research has a worldwide focus and is not limited to the countries with the strongest economies or most abundant and well-known tourism attractions and resources. However, it also shows certain world regions were under-represented or had no tourism research focus in academic journals from 2002-2011. These include parts of Central-Northern Africa and South-Central America, the Central Asian republics, some Eastern European countries, and the Caucasus.

\section{[Insert Figure 2 about here]}

For Asia, China (656), Taiwan (179), and South Korea (132) had the highest frequencies. Other Asian destinations with significant frequencies were Japan (84), Thailand (83), India (81), Singapore (53), Malaysia (42), and Indonesia (42). Australia (363) and New Zealand (125) had strong representation in the dataset. For other countries in Oceania such as Papua New Guinea, Fiji, Samoa, and Vanuatu, the frequencies were below 10.

According to UNWTO (2014a) statistics, the Asia and the Pacific region is gaining market share in tourism worldwide, while Europe's market share is declining. International tourist arrivals to the Asia and the Pacific region grew by $6.2 \%$ to reach 248.1 million in 2013. The international tourism receipts for China, Macau, Thailand, and Hong Kong ranked among the top 10 in the world in 2013. China has also attained the first rank position in tourism expenditures abroad by its residents UNWTO, 2014b). Given these recent trends, it is understandable why more tourism research has recently focused on the Asia-Pacific region. Afghanistan, Bangladesh, Brunei, Pakistan, and Timor-Leste were the only Asian countries not covered in these journals from 2002-2011, in addition to several of the Central Asian republics (Kazakhstan, Turkmenistan, and Uzbekistan).

The UK (384) and Spain (170) had the highest frequencies among European countries, followed by Turkey (155), Greece (66), Italy (55), Cyprus (50), and Portugal (50) (Figure 3). According to UNWTO statistics, Spain and the UK are among the world's top 10 countries in terms of tourist arrivals and receipts (UNWTO, 2014b). Belarus, Luxembourg, Latvia, and Serbia were among the European countries with no geographic keywords or titles in the 32 journals. Some countries in the Caucasus were also not represented including Azerbaijan and Georgia. France (37), Germany (31), and Russia (9) appeared to be underrepresented in this database especially given their tourism attractions and resources, large population bases, sizes of tourist markets, and advanced economic development status. It is suspected that language may be one of the reasons for this finding. 


\section{[Insert Figure about 3 here]}

The strong research focus on China is a remarkable finding of this research. Overall, the Asia-Pacific region predominated in this database accounting for around $43.2 \%(2,009)$ of the articles (Table 3). Europe was in second place with approximately $29.4 \%$ or 1370 articles. North America accounted for $15.2 \%$ with a combined frequency of 712 articles on the USA (549), Canada (126), and Mexico (37). For this research, the Caribbean was counted separately and Central America was combined with South America.

Africa was in fourth place with $5.2 \%$ of the articles and the combined frequency for the African countries was 243. South Africa (45), Kenya (38), Egypt (31), Mauritius (18), and Nigeria (17) had the highest counts among African countries. However, only 23 of the 55 countries in Africa were included in this database.

The Middle East with a combined frequency of 132 articles took the fifth place. Israel (45) and Palestine (18) ranked top two in terms of article frequency among ten Middle Eastern areas.

There were slightly fewer articles (110) on the South and Central America than on the Middle East. Brazil (23), Costa Rica (16), and Peru (8) accounted for more than half of geographic references for South and Central America. Honduras, Panama, and Uruguay had no keywords.

Several Caribbean island nations had geographic references including Antigua and Barbuda, Aruba, Bahamas, Barbados, Cuba, Dominican Republic, Grenada, Jamaica, St. Lucia, and Trinidad \& Tobago. Cuba (18), Jamaica (16), and Barbados (14) had the highest frequencies. Obviously there were several Caribbean island countries missing in the database. The region with the lowest share of the articles was Antarctica.

These research findings are perhaps as important as that of the predominance of the Asia-Pacific region, in suggesting that some important world regions are being neglected by tourism scholars. Discovering the reasons for this under-representation will be a worthwhile future research endeavor.

\subsection{The co-occurrence relationships among research focus countries}

A certain proportion of these tourism research articles contained more than one research focus country. These studies, for example, explored the perception of tourists toward destinations (Truong, 2005); cross-cultural tourism (Getz, Andersson, \& Carlsen, 2010); tourism and immigration (Stodolska \& Santos, 2007); and the comparative study of countries (Kozak, 2002). If two country references appeared in the same article, it meant the countries had a co-occurrence relationship. Overall, 368 research articles in the database had more than one geographic references in a single 
paper. This research analyzed the co-occurrence of 86 focus countries forming 240 pairs of co-occurrence relationship. A NetDraw relationship map was drawn and is shown in Figure 4. The line widths demonstrate the strength of the co-occurrence relationships between pairs of countries and the number indicates how many articles included these pairs of countries. The layout of this map is based on principal components and it can be seen that the USA is the country with the most intensive co-occurrence network, having 34 relationship lines. It is followed by Australia, the UK and China with 23 lines respectively. The third highest grouping is comprised of Spain (18), India (16), Japan (16), South Korea (16), New Zealand (16), France (15), Germany (15), Canada (13), and Hong Kong (12). Some 25 countries only had one relationship line with other countries and most were countries located in Asia and Europe.

\section{[Insert Figure 4 about here]}

Based on the NetDraw analysis, the top four focus countries China, USA, UK, and Australia were also the most intensive nodes in the relationship network map, demonstrated by the layout where they are on the far left with intensive lines around them. China, Japan, South Korea, Hong Kong, and some other Asian countries were closer to each other at the top of the map while the UK, Spain, France, Germany, and other European countries gathered at the bottom of the map. This suggested that geo-relationships are important in tourism research and the closer geographically are the countries and the more interconnected are their cultures and histories, the greater is the tourism research conducted among them.

The co-occurrences of the USA and China (26), China and Hong Kong (22), China and Australia (20), the USA and Canada (18), the USA and Japan (16), Australia and the UK (11), the UK and Turkey (11), and China and Canada (10), were particularly strong. Several research articles took the USA and other countries as a combined focus. Apart from the stronger relationships with China, Canada and Japan, these co-occurrences were only of moderate strength less than 10. The UK had relationships with most of the European countries as well as with more distant countries. However, with the exception of the stronger relationships with Australia and Turkey, the UK had relatively weak co-occurrence relationships with China, New Zealand, and the USA.

\subsection{Most popular research topics of research focus countries}

This analysis also investigated the most popular research topics according to research focus countries. It was recognized that if the keyword frequencies were too low, this would adversely influence the research results and their interpretation. Therefore, only the top 10 countries ranked by frequencies were selected for this 
analysis. A separate database was created including all the research articles for these countries and their keywords were analyzed according to the modified tourism system. Each article was coded into one of 53 sub-categories based on a review of its title and keywords. If an article had broader coverage and could not be sorted into only one sub-category, it was coded into more than one sub-category to prevent information loss. Table 4 shows the relative popularity of research topics for the 10 research focus countries with the highest frequencies.

Overall among the top 10 highest frequency countries, the highest proportion $(43.4 \%)$ of the research articles in the database were in the destination topic category, followed by demand (25.7\%) and marketing (25\%). China (58.2\%), Turkey (51.1\%), and South Korea (52.6\%) had more of a research focus on destinations. For the demand topic category, the destinations with the highest proportions were Taiwan $(41.3 \%)$ and Canada (39.1\%), and the USA (30.7\%) and Australia (31.3\%) had the highest proportions for the marketing topic category. There could be many reasons for these differences including variations in the stages of tourism development.

At the earliest stages, a research focus on the physical tourism resources in destinations might be expected especially. In later stages and particularly in developed countries, it may be anticipated that the research focus would move more towards demand and marketing. As tourism destinations mature, more research is conducted on tourists' images and perceptions, satisfaction levels, and other aspects of tourist behavior. Additionally, with the rapid development of the Internet and social media, an increased emphasis on research related to marketing and distribution channels can be expected. This progression of tourism research cannot be conclusively confirmed from this study's findings and there certainly are other factors, including the disciplinary backgrounds and research interests of scholars, which influence these wide variations in the popularity of research topics for different geographic areas.

\section{[Insert Table 4 about here]}

Table 5 identifies the two sub-categories of research topics with the highest frequencies for the 10 countries. Tourism development research was popular in articles focused on China. Images and perceptions was a popular sub-category for the research on Australia and Turkey; while market segmentation was popular for Australia, Canada, and China; and tourism impacts/impacts were popular for Spain and Taiwan. Marketing-related sub-categories were particularly popular for research on the USA (marketing mix), UK (marketing strategy and plans), Spain (marketing strategy and plans), and Hong Kong (distribution channels).

Some focus countries had a distinctive concentration on individual sub-categories of research including the UK (tourism management), Turkey (human resources), and South Korea (policy and government). The impact of certain prolific scholars on these 
results is acknowledged for some countries.

\section{[Insert Table 5 about here]}

The relationships of types of tourism and research focus countries were also investigated and the results are shown in Table 6. Overall, the types of tourism most addressed in this database were sustainable tourism, ecotourism, heritage tourism, rural tourism, and casino. It was also noteworthy that the research articles on these types of tourism and especially on sustainable tourism and ecotourism were from many countries. The research articles with a focus on China tended to cover types of tourism related to its cultural-heritage resources including cultural tourism, heritage tourism, ethnic tourism, and rural tourism. The types of tourism in the Australia-based research were more focused on its natural resources. Festival tourism was most popular in the research on the UK and Australia. Pro-poor tourism as would be expected had the most research emphasis for the developing countries.

\section{[Insert Table 6 about here]}

\section{Conclusions and discussion}

There was a broad geographic focus of the research in tourism, hospitality and leisure journals in the decade from 2002-2011 spanning 134 different territories. It was also found that a significant number of nations were not covered in this 10 -year snapshot of the academic journal research and require more attention from scholars in the future. Some major countries seemed to be under-represented including France, Germany, and Russia. However, the predominance of the research focus on the Asia-Pacific region and particularly on China was a major finding in this analysis. The sparse coverage of research on Africa countries was another major result.

The remarkable prominence of China in this decade's worth of research warrants further discussion and potential explanations, especially since Mainland China is not English-speaking. Partly this can be attributed to the rapid growth in the domestic, outbound, and inbound tourist markets for Mainland China. This has undoubtedly piqued the interest in China-based research among scholars worldwide. In particular, the scale and spending power of the outbound tourist market from China is affecting many countries. The rapid tourism development within China combined with its massive domestic market and growing international tourist arrivals presents a set of unique lures for academic researchers. The "export" of several prominent Chinese-born scholars to other countries is another partial explanation, as several of them made major contributions to this research literature in 2002-2011. Moreover, the strong collaborative behavior of Chinese scholars within and outside of China with international colleagues has been a catalyst for research on China. Many of the 
articles including China in their keywords had Chinese first authors followed by second and successive authors from other countries. Even when living and working abroad, most Chinese scholars maintained their research attachment with the country of their birth and location of their initial rounds of higher education.

The high frequency levels for Hong Kong and Macau were notable side-by-side the large number of articles about Mainland China. Again these findings are worthy of more investigation. In addition to being a major tourism destination, Hong Kong has several highly productive research scholars whose rates of output flourished during 2002-2011. The "Macau miracle" of fast-paced tourism investment and market growth mainly fueled by casino development has attracted the attention of local and foreign scholars. Taken together, approximately $15 \%$ of all the articles in the database featured Mainland China, Hong Kong, and Macau.

The research focus countries were comprised of both developed and developing nations. However, there was unbalanced coverage according to major geographic regions of the world. Approximately $88 \%$ of the articles were from just three regions, the Asia-Pacific, Europe, and North America. The other parts of the world including Africa, the Middle East, and South and Central America appeared to be under-served by academic research in 2002-2011. There are several potential reasons for this phenomenon including lesser amounts of collaborative research partnerships between scholars from these regions and their counterparts abroad. Language may be another limiting factor as well as perceived lesser attractiveness of the regions for conducting research among foreign scholars.

It was concluded that the frequencies of research articles for certain countries were significantly lower than would be expected. This was especially so for France, Germany, and Russia, and to some extent also for Italy. France is the top tourism destination in the world in terms of total tourist arrivals and ranks third in international tourism receipts (UNWTO, 2013b). France also has a long and rich history of tourism scholarship. However, a review of this database showed that the authors of English articles were seldom French or based in France. The research team conducted follow-up interviews with some French scholars and found their major challenge was in using English in academic journal articles. The French scholars found it more convenient to publish articles in local journals rather than in English-language journals. Moreover, there was less encouragement and incentives from their universities to publish in English-language journals. Through experience and observation, there are relatively fewer French scholars studying tourism, hospitality and leisure abroad and this is another constraint to collaboration with English-speaking scholars.

Based on NetDraw analysis, USA, China, UK, and Australia were the most intensive nodes of co-occurrence relationship networks. The results demonstrated that 
geo-relationships were important in patterns of coverage of individual countries in tourism research. Geographic proximity and the strength of historic and cultural ties appeared to be influential factors for influencing co-occurrence relationships.

Another conclusion was that there is a relationship between geography and the most popular topics in tourism research. Developing countries in the earlier stages of tourism development tended to have more research articles related to destinations. This seems understandable given the presence of sub-categories within destinations such tourism impacts/impacts, resource management, and various aspects of tourism products. More mature tourism countries had more research focused on demand and marketing including images and perceptions and market segmentation.

\section{Limitations}

There are several limitations to this research that need to be acknowledged. Many journal articles include no geographic references as indicated in this analysis. It is not possible to determine whether authors intentionally or unintentionally excluded geographic references, or if they intended their works to apply nationally, regionally, or worldwide without specifically stating their intent. It is acknowledged that some countries may be under-counted in this analysis because authors decided not to include geographic references, and this is thought to be the case for some of the research applying to the U.S. Moreover, it is recognized that research articles that are attempts to derive, develop, or test theories and concepts are without geographic contexts.

This research elected to use a tourism systems approach for categorizing the research in the 32 journals. Several other classification schemes could have been applied and this is undoubtedly a limitation of this work. Since the main focus of this research was on the geographic scope of published academic articles, and knowing that world regions and countries are at different stages of tourism development, the tourism systems approach was judged appropriate for discerning differences in topic coverage among countries. It is recognized that the application of other categorization frameworks will contribute added depth and richness to this analysis of tourism, hospitality, and leisure research journals.

The database of articles for this research was constrained to a set of journals $(n=$ 32) and a specific time period (2002-2011). It is acknowledged that there are at least 40 other English-language tourism, hospitality, and leisure journals that could have been included in this analysis. English-language academic journals have existed for 40-plus years, but this research only provided a 10-year snapshot of the research. It is very likely that tourism, hospitality, and leisure research has evolved over the past four or five decades, and the present portrayal of geographic scope and topics is 
probably not representative of prior decades.

\section{Contributions, implications and future research}

\subsection{Contributions}

The major contribution of this research was the broad scope of the geographic analysis across a large number of tourism, hospitality and leisure journals. Although there has been some previous research that has categorized keywords by regions and countries, it has been far less extensive and did not consider country co-occurrence relationships. In addition, although prior studies have analyzed research topics for individual countries, the current analysis did this across 10 different countries and shed more light on variations in research topic emphasis.

This analysis has highlighted the countries and regions on which tourism research has focused the most in the decade from 2002-2011. The prominence of the Asia-Pacific region in tourism research is consistent with the rapid growth in the region's tourism arrivals and tourists, and also mirrors the strong tourism development that has taken place especially in China and parts of Southeast Asia. According to UNWTO, the Asia and the Pacific region accounted for $23 \%$ of the world's total international tourist arrivals; its share of the articles in this analysis was $43.2 \%$. Although Europe commanded a 52\% share of world tourist arrivals in 2012, its proportion of tourism research was just 29.4\% (UNWTO, 2013b).

Although it may have been surmised from knowing generally what gets published in these journals, this research has highlighted the lack of attention to South and Central America in the body of English-language literature. Economic and social conditions have a great influence on tourism activities and tourism research, so they have relevance to research focus countries. This is especially unfortunate given the poor economic and social conditions in South and Central America, as well as in the many African nations not found in this database.

\subsection{Implications}

One of the findings of this analysis is that there is not a uniform or even coverage of the countries in the world in tourism research. Although this is as might be expected, it does not necessarily represent an ideal situation for the scholarship of tourism. It will be desirable in the future if more ways can be found to capture tourism research from the developing countries and from other major languages, particularly French, German, Russian, Italian, Spanish, Chinese, Turkish, and Thai, which are official languages of the top ten international tourism destinations and Portuguese 
which is the fastest-growing European language after English, into the English-language research literature. Unfortunately, some previous attempts at bilingual journals have not been successful.

In the decades ahead, if history repeats itself, then it may be expected that tourism scholars' focus will be on the growth geographic areas in the world, which are expected to be in the Asia-Pacific, Africa, and the Middle East.

\subsection{Recommendations for future research}

There are future opportunities to expand upon the scope of this research by analyzing more tourism, hospitality, and leisure journals, as well as covering different time periods. Forty-plus other English-language journals could be analyzed in the future and thought should be given to shedding more light on the historic coverage of journals in the 1970s, 1980s, and 1990s, and comparing the results with those of this research.

A tourism systems approach was employed herein to categorize the journal research but future researchers should apply other research frameworks to enrich the understanding of the scope of tourism research. Using theoretical, conceptual, and analytical (methodological) frameworks will certainly offer valuable perspectives.

There is a need for more future research on several countries under-represented or not even identified in this research database. This is more likely to happen if greater incentives are given to scholars to expand the geographic scope of their research and collaborations. Greater emphasis on tourism research by national governments in the under-served countries and more emphasis on international research partnering by their local universities could be the catalysts for bringing scholars and their graduate students closer together.

\section{References}

Ashworth, G., \& Page, S. J. (2011). Urban tourism research: recent progress and current paradoxes. Tourism Management, 32(1), 1-15.

Ballantyne, R., Packer, J., \& Axelsen, M. (2009). Trends in tourism research. Annals of Tourism Research, 36(1), 149-152.

Banville, C., \& Landry, M. (1989). Can the field of MIS be disciplined? Communications of the ACM, 32(1): 48-60.

Benckendorff, P., \& Zehrer, A. (2013). A network analysis of tourism research. Annals of Tourism Research, 43, 121-149. 
Borgatti, S. P., (2002). NetDraw Software for Network Visualization. Analytic Technologies: Lexington, Kentucky.

Botterill, D., Haven, C., \& Gale, T. (2002). A survey of doctoral theses accepted by universities in the UK and Ireland for studies related to tourism, 1990-1999. Tourist Studies, 2(3), 283-311.

Broadus, R. N. (1987). Toward a definition of "bibliometrics". Scientometrics, 12(5/6), 373-379.

Chen, C.-C., \& Schwartz, Z. (2006). The importance of information asymmetry in customers' booking decisions: A cautionary tale from the Internet. Cornell Hotel and Restaurant Administration Quarterly, 47(3), 272-285.

Cheng, C.-K., Li, X., Petrick, J. F., \& O'Leary, J. T. (2011). An examination of tourism journal development. Tourism Management, 32(1), 53-61.

Crawford-Welch, S., \& McCleary, K. W. (1992). An identification of the subject areas and research techniques used in five hospitality-related journals. International Journal of Hospitality Management, 11(2), 155-167.

Crichton, K. (1978). Dissertations on travel, recreation and leisure. Journal of Travel Research, 17(1), 14-22.

Dai, B., Tang, X.-Y., Du, X.-S. (2011). Review on China tourism research in 2010: based on analysis of 18 domestic tourism-related journals. China Tourism Review. Beijing: Tourism Education Press.

Dann, G., Nash, D., \& Pearce, P. (1988). Methodology in tourism research. Annals of Tourism Research, 15(1), 1-28.

Edwards, D., Griffin, T., \& Hayllar, B. (2008). Urban tourism research: developing an agenda. Annals of Tourism Research, 35(4), 1032-1052.

Faulkner, B., \& Ryan, C. (1999). Innovations in tourism management research and conceptualization. Tourism Management, 20(1), 3-6.

Frechtling, D. C. (2004). Assessment of tourism/hospitality journals' role in knowledge transfer: An exploratory study. Journal of Travel Research, 43(2), 100-107.

Getz, D., Andersson, T., \& Carlsen, J. (2010). Festival management studies: Developing a framework and priorities for comparative and cross-cultural research. International Journal of Event and Festival Management, 1(1), 29-59.

Gunn, C. (1972). Vacationscape: Designing Tourist Regions. Austin: Bureau of 
Business Research, University of Texas.

Gunn, C. A., \& Var, T. (2002). Tourism Planning: Basics Concepts Cases (4th ed). New York: Routledge.

Hall, C. M. (2011). Publish and perish? Bibliometric analysis, journal ranking and the assessment of research quality in tourism. Tourism Management, 32(1), 26-27.

Hu, C., \& Racherla, P. (2008). Visual representation of knowledge networks: A social network analysis of hospitality research domain. International Journal of Hospitality Management, 27(2), 302-312.

Jafari, J., \& Aaser, D. (1988). Tourism as the subject of doctoral dissertations. Annals of Tourism Research, 15(3), 407-429.

Jafari, J. (ed.) (2000). Encyclopedia of Tourism. Routledge: London.

Jafari, J., \& Xiao, H. (eds.) (2015). Encyclopedia of Tourism. Springer: New York.

Jamal, T., Smith, B., \& Watson, E. (2008). Ranking, rating and scoring of tourism journals: interdisciplinary challenges and innovations. Tourism Management, 29(1), 66-78.

Jogaratnam, G., Chon, K., McCleary, K., Mena, M., \& Yoo, J. (2005a). An analysis of institutional contributors to three major academic tourism journals: 1992-2001. Tourism Management, 26(5), 641-648.

Jogaratnam, G., McCleary, K. W., Mena, M. M., \& Yoo, J. J.-E. (2005b). An analysis of hospitality and tourism research: Institutional contributions. Journal of Hospitality \& Tourism Research, 29(3), 356-371.

Kim, Y., Savage, K. S., Howey, R. M., \& Van Hoof, H. B. (2009). Academic foundations for hospitality and tourism research: A reexamination of citations. Tourism Management, 30(5), 752-758.

Kozak, M. (2002). Measuring comparative destination performance: A study in Spain and Turkey. Journal of Travel \& Tourism Marketing, 13(3), 83-110.

Lee, H. A., \& Law, R. (2011). Research productivity and institutional characteristics of hospitality and tourism programs. Journal of Travel \& Tourism Marketing, 28(4), 432-450.

Leiper, N. (1979). The framework of tourism. Annals of Tourism Research, 6(1): 390-407.

Leung, D., Leung, R., Bai, B., \& Law, R. (2011). Asian wave in travel and tourism research. Journal of Travel \& Tourism Marketing, 28(2), 196-209. 
Lew, A. A. (1987). A framework of tourist attraction research. Annals of Tourism Research, 14(4), 553-575.

McKercher, B. (2005). A case for ranking tourism journals. Tourism Management, 26(5), 649-651.

McKercher, B., \& du Cros, H. (2003). Testing a cultural tourism typology. International Journal of Tourism Research, 5(1), 45-58.

McKercher, B., Law, R., \& Lam, T. (2006). Rating tourism and hospitality journals. Tourism Management, 27(6), 1235-1252.

Meyer-Arendt, K. J., \& Justice, C. (2002). Tourism as the subject of North American doctoral dissertations, 1987-2000. Annals of Tourism Research, 29(4), 1171-1174.

Mill, R. C., \& Morrison, A. M. (1985). The Tourism System. Englewood Cliffs, NJ: Prentice-Hall, Inc.

Mill, R. C., \& Morrison, A. M. (2012). The Tourism System (7th ed). Dubuque, IA: Kendall Hunt Publishing Company.

Morrison, A. M. (2004). Tourism, hospitality and leisure journals (http:// omni.cc.purdue.edu/alltson/journals.htm).

Murphy, J., \& Law, R. (2008). Google scholar visibility and tourism journals. Annals of Tourism Research, 35(4), 1078-1082.

Palmer, A. L., Sesé A., \& Montaño, J. J. (2005). Tourism and statistics: Bibliometric study 1998-2002. Annals of Tourism Research, 31(1), 167-178.

Park, K., Phillips, W. J., Canter, D. D., \& Abbott, J. (2011). Hospitality and tourism research rankings by author, university, and country using six major journals. Journal of Hospitality \& Tourism Research, 35(3), 381-416.

Pearce, D. G. (2001). An integrative framework for urban tourism research. Annals of Tourism Research, 28(4), 926-946.

Pearce, D. G. (2012). Frameworks for Tourism Research. Wallingford, England: CABI.

Pechlaner, H., Zehrer, A., Matzler, K., \& Abfalter, D. (2004). A ranking of international tourism and hospitality journals. Journal of Travel Research, 42(4), 328-332.

Philip, S., Hunter, C., \& Blackstock, K. (2010). A typology for defining agritourism. Tourism Management, 31(6), 754-758. 
Pritchard, A. (1969). Statistical bibliography or bibliometrics? Journal of Documentation, 25(4), 348-349.

Racherla, P., \& Hu, C. (2010). A social network perspective of tourism research collaborations. Annals of Tourism Research, 37(4), 1012-1034.

Reid, L. J., and Andereck, K. L. (1989). Statistical analyses use in tourism research. Journal of Travel Research, 28(2), 21-24.

Rivera, M. A., \& Upchurch, R. (2008). The role of research in the hospitality industry: A content analysis of the IJHM between 2000 and 2005. International Journal of Hospitality Management, 27(4), 632-640.

Ryan, C. (2005). The ranking and rating of academics and journals in tourism research. Tourism Management, 26(5), 657-662.

Samenfink, W. H., \& Rutherford, D. G. (2002). Most frequent contributors to the hospitality literature: A ten-year update. Journal of Hospitality and Tourism Education, 14(3), 5-15.

Schmidgall, R. S., \& Woods, R. H. (1993). Rating of publishing channels by hospitality faculty. Journal of Hospitality \& Tourism Research, 16(3), 89-103.

Severt, D. E., Tesone, D. V., Bottorff, T. J., \& Carpenter, M. L. (2009). A world ranking of the top 100 hospitality and tourism programs. Journal of Hospitality \& Tourism Research, 33(4), 451-470.

Sheldon, P. J. (1990). Journals in tourism and hospitality: The perceptions of publishing faculty. Journal of Tourism Studies, 1(1), 42-48.

Sheldon, P. J. (1991). An authorship analysis of tourism research. Annals of Tourism Research, 18(3), 473-484.

Stodolska, M., \& Santos, C. A. (2007). Transnationalism and leisure: Mexican temporary migrants in the U.S. Journal of Leisure Research, 39(4), 143-167.

Stone, P. R. (2006). A dark tourism spectrum: towards a typology of death and macabre related tourist sites, attractions and exhibitions. Tourism: An Interdisciplinary International Journal, 54(2), 145-160.

Sun, Y.-Y. (2007). Adjusting input-output models for capacity utilization in service industries. Tourism Management, 28(6), 1507-1517.

Svensson, G., Svaeri, S., \& Einarsen, K. (2009). 'Empirical characteristics' of scholarly journals in hospitality and tourism research: An assessment. International Journal of Hospitality Management, 28(3), 479-483. 
Trauer, B. (2006). Conceptualizing special interest tourism - frameworks for analysis. Tourism Management, 27(2), 183-200.

Tribe, J., \& Xiao, H. (2011). Developments in tourism social science. Annals of Tourism Research, 38(1), 7-26.

Truong, T.-H. (2005). assessing holiday satisfaction of Australian travellers in Vietnam: An application of the HOLSAT model. Asia Pacific Journal of Tourism Research, 10(3), 227-246.

UNWTO. (2014a). UNWTO World Tourism Barometer, Volume 12 April 2014. UNWTO: Madrid.

UNWTO. (2014b). UNWTO Tourism Highlights 2014 Edition. UNWTO: Madrid.

Uriely, N., Yonay, Y., \& Simchai, D. (2002). Backpacking experiences: a type and form analysis. Annals of Tourism Research, 29(2), 519-537.

U.S. Department of State. (2013). Independent States in the World.

\section{http://www.state.gov/s/inr/rls/4250.htm}

Van Doren, C. S., Koh, Y. K., \& McCahill, A. (1994). Tourism research: a state-of-the-art citation analysis (1971-1990). In A. V. Seaton (Ed.), Tourism: The state of the art (pp. 308-315). Chichester: John Wiley \& Sons.

Wu, B.-H., Xiao, H.-G., Dong, X.-L., Wang, M., \& Xue, L. (2012). Tourism knowledge domains: A keyword analysis. Asia Pacific Journal of Tourism Research, 17(4), 355-380.

Xiao, H., and Smith, S. L. J. (2005). Source knowledge for tourism research. Annals of Tourism Research, 32(1), 272-275.

Xiao, H., \& Smith, S. L. J. (2006). The making of tourism research: insights from a social sciences journal. Annals of Tourism Research, 33(2), 490-507.

Xiao, H., \& Smith, S. L. J. (2008). Knowledge impact: An appraisal of tourism scholarship. Annals of Tourism Research, 35(1), 62-83.

Xiao, H., Li, M., \& Lin, E. C. K. (2011). Diffusion patterns and knowledge networks: an inductive analysis of intellectual connections in multidisciplinary tourism studies. Journal of Travel \& Tourism Marketing, 28(4), 405-422.

Ye, Q., Li, T., \& Law, R. (2013). A coauthorship network analysis of tourism and hospitality research collaboration. Journal of Hospitality \& Tourism Research, 37(1), 51-76.

Yin, X.-X., Zhang, G.-P., \& Li, X.-F. (2009). Research on research status of 
information science based on keywords analysis. Journal of Intelligence, 28(11), $1-4$. 